\title{
Purpose in life (ikigai) may improve obesity caused by stress: a proposal based on traits of neurotransmitters related to emotions
}

\author{
Riichiro Ishida \\ Akasabi, Nishikan-ku, Niigata 953-0042, Japan
}

\begin{abstract}
This paper aims to propose a way to improve obesity using purpose in life (PIL/ikigai) in view of the chemical traits of neurotransmitters such as serotonin, dopamine, noradrenalin, and $\beta$-endorphin related to emotions. Any stress, such as troubles in human relationships, causes anxiety that may relate to an imbalanced secretion of neurotransmitters. Every person has a need to establish meaning in his/her life, i.e., PIL/ikigai, intrinsically. PIL/ikigai is a prefrontal lobe function developed through evolutionary processes. Therefore, PIL/ikigai is a natural and mentally healthy way to cope with stress and causes well-balanced secretion of neurotransmitters. Obesity causes serious diseases such as cardiovascular disease and diabetes and sometimes leads to death. One of factors influencing obesity is binge eating caused by stress, i.e., anxiety. Binge eating may be an alternative to PIL/ikigai in the secretion of neurotransmitters relating to pleasure and comfort. Therefore, PIL/ikigai may reduce binge eating and lead to decreasing obesity.
\end{abstract}

Keywords-Purpose in life (PIL)/ikigai, stress, emotion, neurotransmitters, obesity

\section{INTRODUCTION}

All people need happiness, including pleasure, comfort, and decreased anxiety over a period of time [1, 2]. These emotions are indicators of continuous successful adaptation to the environment [3]. Any stress, such as trouble in human relationships, causes anxiety [e.g., 3] that is accompanied by changes in the autonomic nervous function controlling homeostasis, as stated by Cannon [4], and by dysfunction of the endocrine system $[5,6]$. Anxiety is an indicator of unsuccessful adaptation to environments [3]. Variation of emotion depends on the secretion of neurotransmitters such as serotonin, dopamine, vasopressin, oxytocin, $\beta$-endorphin, and noradrenaline $[7,8]$. People with anxiety attempt to search for pleasure and comfort. Eating $[9,10]$ and drinking alcohol [11] cause temporary pleasure and comfort because neurotransmitters related to pleasure and comfort are secreted [9-11]. Additionally, drinking alcohol increases appetite resulting in increasing food intake [12-14]. Binge eating is an important risk factor for obesity as is decreased exercise [10,12, 15]. Genetic factors also cause obesity [16]. Obesity causes serious cardiovascular disease and diabetes and sometimes leads to death [17, 18]. Therefore, a fundamental treatment of obesity should be developed.

Every person has a need to establish a meaningful life $[19,20]$. Recently it has been recognized that a meaningful life, i.e. purpose in life (PIL)/ikigai, is a natural and mentally healthy way to cope with stress in a stressful society [e.g., 3]. Additionally, PIL/ikigai may improve alcohol dependence often caused by stress, including anxiety [21]. This process causes well- balanced secretion of neurotransmitters relating to emotions [e.g., 3]. Therefore, we hypothesize that PIL/ikigai is an effective way to reduce binge eating and lead to decreasing obesity. In this paper, we discuss the correlation between PIL/ikigai and obesity based on previous studies including brain function, emotions, and neurotransmitters [7, 8, 22]

\section{EMOTIONS AND NEUROTRANSMITTERS}

In recent years, brain research on the relationships between emotion and neurotransmitters has been remarkably advanced $[7,8,22]$. Dopamine is a neurotransmitters related to motivation and pleasure $[7,8]$. Noradrenaline relates to anxiety. $\beta$-endorphin relates to pleasure and comfort. Vasopressin and oxytocin are related to increasing warm-hearted human relationships. Serotonin is believed to function in the well-balanced secretion of these other neurotransmitters; this function leads to a stable emotion state, i.e., comfort. Understanding the correlation between emotions and neurotransmitters could provide a way to solve the obesity issue. 


\section{CHARACTER OF STRESS}

Any stress, including ones such as trouble with human relationships, kaleidoscopic sound, and changes in temperature [5, 6], causes anxiety and decreases pleasure and comfort [e. g., 3]. Serious and continuous failure of coping with stress influences the autonomic nervous function controlling homeostasis [4] and the function of the endocrine system [5,6], and sometimes results in mental and somatic disease accompanied by death $[5,6]$. Anxiety causes an imbalanced secretion of neurotransmitters and leads people to attempt to change their state from uncomfortable to comfortable in various ways $[3,4,5,6]$. One of the ways includes eating and alcohol-induced increased eating [14]. Binge eating, however, causes obesity [10, 12]. Drinking alcohol can sometimes cause alcohol dependence [23]. Other ways to reduce anxiety include moderate exercise [7] and conversation with familiar persons [24]: these ways are considered as good. A process of evolution provided the human psychological and physiological ability to adapt to environments intrinsically. Cannon [4] noted that, " only by understanding the wisdom of the body, shall we attain that mastery of disease and pain which will enable us to relieve the burden of mankind." Recently, it has been recognized that purpose in life (PIL)/ikigai, which is used by "the wisdom of body" including prefrontal lobe function, is a natural and mentally healthy way to cope with stress [3].

\section{PURPOSE IN LIFE (PIL)/IKIGAI}

The term "purpose in life" came from existential philosophy, which developed in Europe, while "ikigai" appeared in Japanese classical literature. Both PIL and ikigai have long histories and share a common core theme: "Everything changes and life is a one-time opportunity. Every person has a need for a meaningful life [18, 19]." PIL/ikigai relates to ambition, view of life, and mental integration of psychological events [e.g., 3]. The prefrontal lobe has evolved over a long period and has functions such as ambition, view of life, mental integration, and attitude toward stress [20]. Therefore PIL/ikigai could be based on prefrontal lobe function. Previous studies have showed that PIL/ikigai is an effective way to cope with stress. More specifically, persons with firm PIL/ikigai can better decrease anxiety, mental and somatic subjective symptoms and increase pleasure and comfort even in stressful situations and society compared with persons with weak PIL/ikigai [25]. Furthermore, persons with PIL/ikigai have distinct personality traits: having lower social desirability, which is an attitude based on the need for approval and an attempt to adapt excessively to expectation of their society; attaining their purpose with enthusiasm and patience and without impulse; respecting the personality of other persons; and having an more independent spirit [3, 21, 26, 27]. These personality traits show that they can satisfy their mind with pleasure and comfort based on intrinsic aspects of controlled secretion of neurotransmitters. Therefore PIL/ikigai may be an effective way to decrease binge eating caused by stress and lead to reducing obesity as well as alcohol dependence.

Persons with firm PIL/ikigai have positive experiences such as spending and playing sufficiently in beautiful nature including mountains, forests, rivers, and marshes; accepting warm hearted support without forcing directions from others, and being improved by persons and events [3, 24].

\section{STUDY LIMITATIONS}

These proposals for improvement of obesity are not based on experiments but on a hypothesis created by adding previous individual pieces of evidence. Additionally, more factors influencing obesity should be considered. Therefore, further studies relating PIL/ikigai to improvement in obesity should be performed.

\section{CONCLUSION}

Successful coping with stress causes a well-balanced secretion of neurotransmitters related to emotions. Unsuccessful coping with stress causes an imbalanced secretion of these neurotransmitters. People with unsuccessful coping with stress, i.e. anxiety, sometimes show binge eating and over consumption of alcohol because both behaviors cause secretion of neurotransmitters related to pleasure and comfort. Binge eating and over consumption of alcohol may easily result in obesity and alcohol dependence accompanied by serious diseases. PIL/ikigai is a prefrontal lobe function that causes well-balanced secretion of neurotransmitters related to emotions during stressful situations. This indicates PIL/ikigai is a natural and mentally healthy way to cope with stress. Therefore, PIL/ikigai may be an effective way to decrease binge eating and thus reduce obesity. 
Purpose in life (ikigai) may improve obesity caused by stress: A proposal based on traits...

\section{REFERENCES}

[1]. Hills, P. and Argyle, M. (2001). Emotional stability as a major dimension of happiness. Personality and Individual Differences, 3, 1357-1364.

[2]. Argyle, M. and Crossland, J. (1987). Dimensions of positive emotions. The British Journal of Social Psychology, 26, 127-137.

[3]. Ishida, R. (2012). Purpose in life (ikigai), a frontal lobe function, is a natural and mentally healthy way to cope with stress. Psychology, 3, 272-276.

[4]. Cannon, W. B. (1939). The wisdom of the body. New York, WW Norton and Company.

[5]. Selye, H. (1936). A syndrome produced by diverse nocuous agents. Nature, 138, 32.

[6]. Selye, H. (1973). The evolution of the stress concept. American Psychologist, 61, 692-699.

[7]. Esch,T. and Stefano, G.B. (2010). The neurobiology of stress management. Neuroendocrinology Letters, 31, 19-39.

[8]. Ikuta, S. (2011). Nou to kokoro wo shihai suru bussitsu Tokyo, SoftBank Creative.

[9]. Baranowska, B., Singh, S.P., Soszynski, P., Nowakowski, J., and Jeske, W. (1987). The role of opiate, dopaminergic, and adrenergic systems in the hypothalamo-pituitary dysfunction in obesity. Acta Endocrinologica, 116, 221-228.

[10]. Ericsson, M., Poston, W. S. $2^{\text {nd }}$, and Foreyt, J.P. (1996). Common biological pathways in eating disorders and obesity. Addictive Behaviors, 21, 733-743.

[11]. D’Addario, C., Johansson, S., Candeletti, S., Romualdi, P., Ögren, S. O., Terenius, L., and Ekström, T. J. (2011). Ethanol and acetaldehyde exposure indices specific epigenetic modifications in the prodynorphin gene promoter in a human neuroblastoma cell line. FASB Journal, 25, 1069-1075.

[12]. Lloyd-Richardson, E. E., Lucero, M. L., Dibello, J. R., Jacobson, A. E., and Wing, R. R. (2008). The relationship between alcohol use, eating habits and weight change in college freshmen. Eating Behaviors, 9, 504-508.

[13]. Yeomans, M. R., Caton, S., and Hetherington, M. M. (2003). Alcohol and food intake. Current Opinion in Clinical Nutrition and Metabolic Care, 6, 639-644.

[14]. Fischer, S., Anderson, K. G., and Smith, G. T. (2004). Coping with distress by eating or drinking: Role of trait urgency and expectancies. Psychology of Addictive Behaviors, 18, 269-274.

[15]. Gremeaux, V., Drigny, J., Nigam, A., Juneau, M., Gulibeault, V., Latour, E., and Gayda, M. (2012). Long-term lifestyle intervention with optimized high-intensity interval training improves body composition, cardiometabolic risk, and exercise parameters in patients with abdominal obesity. American Journal of Physical Medicine \& Rehabilitation, 30.

[16]. Rhee, K.E., Phelan, D., and McCaffery, J. (2012). Early determinants of obesity: Genetic, epigenetic, and in utero influences. International Journal of Pediatrics, doi: 10.1155/2012/463850

[17]. Baretić, M. (2012). Targets for medical therapy in obesity. Digestive Diseases, 30, 168-172.

[18]. Camethon, M. R., De Chavbez, P. J., Biggs, M. L., Lewis, C. E., Pankow, J. S., Bertoni, A. G., Golden, S. H., Liu, K., Mukamal, K. J., Campbell-Jenkins, B., and Dyer, A. R. (2012). Association of weight status with mortality in adults with incident diabetes. JAMA, 308, 581-590.

[19]. Frankl, V. E. (1972). The meaning of meaningless: A Challenge to psychotherapy. American Journal of Psychoanalysis, 32, 85-89.

[20]. Kamiya, M. (2004). Ikigai ni tsuite. Tokyo, Misuzu-Shobo.

[21]. Ishida, R. (2012). Proposal to prevent alcohol dependence using purpose in life/ikigai to mimic the chemical effects of $\beta$-endorphin. Psychology, 3, 534-536.

[22]. Brodal, P. (1998). The central nervous system. New York, Oxford University Press.

[23]. Duncan, J., Johnson, S., and Ou, X. M. (2012). Monoamine oxidases in major depressive disorder and alcoholism. Drug Discoveries \& Therapeutics. 6, 112-122.

[24]. Ishizuka,Y., Fukuoka, H., Ishizaki, T., Tanaka, H., and Ishitobi, H. (2004). The implementation of game in a 20day head-down tilting bed rest experiment upon mood status and neurotic levels of rest subjects. Acta Astronautica. 55, 945-952.

[25]. Ishida, R., and Okada, M. (2006). Effects of a firm purpose in life on anxiety and sympathetic nervous activity caused by emotional stress: Assessment by psycho-physiological method. Stress and health, 22, 275-281.

[26]. Ishida, R. (2012). Reducing anxiety in stutterers through the association between "Purpose in Life/Ikigai" and emotions. Global Journal of Health Science, 4, 120-124.

[27]. Ishida, R. (2008). Correlation between social desirability and autonomic nervous function under goal-oriented stress (mental arithmetic) with consideration of parental attitude. The Autonomic Nervous System (Tokyo). 45, 242249. 